\title{
Piperazine-modified magnetic graphene oxide (Pip@MG0) as a novel nanocomposite for the effective removal of lead ions; using RSM optimization
}

\section{Mousa Alboghbeish}

Khorramshahr University of Marine Science and Technology

Seyyed Jafar Saghanezhad

ACECR-Production Technology Research Institute

Arash Larki ( $\nabla$ arash_larki@yahoo.com )

Khorramshahr University of Marine Science and Technology

\section{Research Article}

Keywords: Removal of Pb(II), Nanocomposite, Response surface method, Isotherms, Water treatment

Posted Date: March 7th, 2022

DOI: https://doi.org/10.21203/rs.3.rs-1388276/v1

License: (c) (i) This work is licensed under a Creative Commons Attribution 4.0 International License.

Read Full License 


\title{
Piperazine-modified magnetic graphene oxide (Pip@MGO) as a novel
}

\section{nanocomposite for the effective removal of lead ions; using RSM}

\section{optimization}

\author{
Mousa Alboghbeish ${ }^{\text {a }}$, Seyyed Jafar Saghanezhad ${ }^{\mathrm{b}}$, Arash Larki $^{\mathrm{a} *}$ \\ ${ }^{a}$ Department of Marine Chemistry, Faculty of Marine Science, Khorramshahr University of \\ Marine Science and Technology, Khorramshahr, Iran \\ ${ }^{b}$ ACECR-Production Technology Research Institute, Ahvaz, Iran \\ *Corresponding author. Fax: +98-61-53540405 \\ E-mail: arash_larki@yahoo.com, a.larki@kmsu.ac.ir
}

\begin{abstract}
In this research, the piperazine-modified magnetic graphene oxide
\end{abstract} (Pip@MGO) nanocomposite was synthesized and utilized as a nano-adsorbent for the removal of $\mathrm{Pb}$ (II) ions from environmental water and wastewater samples. The physicochemical properties of Pip@MGO nanocomposite was characterized by XRD, FESEM, TEM, EDX, TGA, VSM and FT-IR analysis. In this method, the batch removal process were designed by response surface methodology (RSM) based on a central composite design (CCD) model. The results indicated that the highest efficiency of $\mathrm{Pb}(\mathrm{II})$ removal was obtained from the quadratic model under optimum conditions of prominent parameters (initial $\mathrm{pH}$ : 6.0, adsorbent dosage: $7 \mathrm{mg}$, initial concentration of lead: $15 \mathrm{mg} \mathrm{L}^{-1}$ and contact time: $27.5 \mathrm{~min}$ ). Adsorption data showed that lead ions uptake on Pip@MGO nanocomposite followed the Langmuir isotherm model equation and pseudo-second order kinetic model. High adsorption capacity $(558.2 \mathrm{mg}$ $\mathrm{g}^{-1}$ ) and easy magnetic separation capability showed that the synthesized Pip@MGO nanocomposite has great potential in removal of $\mathrm{Pb}(\mathrm{II})$ ions from contaminated wastewaters. Keywords: Removal of $\mathrm{Pb}(\mathrm{II})$; Nanocomposite; Response surface method; Isotherms; Water treatment 


\section{Introduction}

Disposal of industrial effluents and wastewaters is considered as one of the most important challenges in the industrial world today. Due to the toxic ingredients of these effluents such as, heavy metal ions and dyes, they are the main cause of pollution of rivers, lakes and underground waters $^{1,2}$. Unlike organic pollutants, heavy metal ions are not only degradable or decomposable but also can accumulate in biotic and abiotic systems through the food chain, drinking water and air, resulting in serious damage to the environment and human safety ${ }^{3}$. The most notorious heavy metals that cause significant environmental pollution are lead, chromium, mercury, cadmium, arsenic, zinc, copper, and nickel. The concentration of some of them have reached dangerous levels both for the environment and humans. Accordingly, reduction of such pollutants is one of the most significant step in wastewater treatment ${ }^{4}$. Among the various toxic metal ions, lead is a highly toxic pollutant that is released into the environment due to industrial activities, including mining, plating, battery production, metal smelting, oil refining, printing, and so on. Acumination of $\mathrm{Pb}$ (II) ions in the human body lead to various health consequences, such as: anorexia, gastrointestinal colic, anemia, neurasthenia, kidney and liver damage, and even cancer ${ }^{5}$. Therefore, in order to environmental clean-up, it is absolutely essential to design appropriate technologies and prepare effective materials for complete removal or reduction of $\mathrm{Pb}^{2+}$ ions to an acceptable level, before discharge ${ }^{6}$.

There are many traditional methods for removing lead, including ions exchange, chemical precipitation, electrodeposition, membrane filtration and reverse osmosis ${ }^{7}$. However, these techniques usually suffer from some limitations including complexity and high cost of their operation, potential secondary pollution, difficulty in recycling and poor efficiency in low concentration of lead ${ }^{8,9}$. Among the various treatment technologies, adsorption is currently preferred as a non-hazardous method for the removal of heavy metal due to its cheapness, selectivity, high efficiency, simple processes, reusability, flexibility in design and availability 
of different adsorbents ${ }^{10}$. Generally, an ideal adsorbent should have a high surface area and also adsorption sites, so that the adsorption process takes place in a short equilibrium time ${ }^{10,11}$. In the last two decades, by the development of novel nanotechnologies and the advent of nanomaterials, scientists have been attracted to this field and various novel adsorbents have been emerged ${ }^{12}$. Due to various advantageous in which appears by reducing the size of the adsorbent to nanometers and increasing the surface area and thus increasing the activities sites, the adsorption capacity of these materials increases significantly ${ }^{13,14}$.

Recently, graphene oxide (GO) as a single-layered two-dimensional (2D) nanomaterial has aroused great interest between analytical chemists due to large surface area, high mobility and good conductivity. GO has been extensively used as an adsorbent in solid phase extraction of various organic and inorganic contaminants ${ }^{15}$. However, the dispersion of GO nanosheets is very high and their separation from the solution medium is very difficult and also time consuming. In order to facilitate separation after the adsorption process, the creation of magnetic properties through the fabrication of magnetic graphene nanocomposites is recommended ${ }^{15-19}$. Generally, $\mathrm{Fe}_{3} \mathrm{O}_{4}$ magnetic nanoparticles have been widely used in the construction of nanocomposite adsorbents in magnetic SPE techniques due to their simplicity in synthesis and ease of application ${ }^{20-23}$, but pure $\mathrm{Fe}_{3} \mathrm{O}_{4}$ nanoparticles are rapidly oxidized in the atmosphere and are not suitable for efficient adsorption in complicated matrices. In order to overcome these limitations and enhance the applicability of these types of adsorbents in real wastewater, the $\mathrm{Fe}_{3} \mathrm{O}_{4}$ surface must be functionalized by a modifier with appropriate functional groups ${ }^{7,24}$. Hence, by designing a solid hybrid of magnetic graphene oxide (MGO) with suitable modifier, a good adsorbent can be prepared to remove pollutants.

The main objective of this work is the evaluation of piperazine-functionalized magnetic graphene oxide (Pip@MGO) nanocomposite for the removal of $\mathrm{Pb}$ (II) from the aqueous environment. The fabricated Pip@MGO nanocomposite was characterized by XRD, FESEM, 
TEM, EDX, TGA, VSM and FT-IR analysis. The most significant parameters in the removal efficiency, including solution $\mathrm{pH}$, initial lead concentration, adsorbent dosage, and contact time, were considered and the optimal values of these variables were evaluated by a statistical approach using response surface methodology (RSM) based on a central composite design (CCD) model. In addition, the isotherm modelling and kinetics parameters were studied to understand the mechanism of adsorption of $\mathrm{Pb}^{2+}$ ions on Pip@ MGO adsorbent.

\section{Experimental}

\subsection{Reagents}

All reagents and chemicals used in this work were of analytical grade, without further purification, and ultrapure distilled water was used in the experiments. The chemicals including, graphite powder, iron(III) chloride hexahydrate, iron(II) chloride tetrahydrate, 3chloropropyltriethoxysilane, piperazine anhydrous, potassium permanganate, hydrogen peroxide (30\%), sulfuric acid (98\%), hydrochloric acid (37\%), sodium hydroxide, toluene

and ethanol were purchased (Merck, Darmstadt, Germany). A stock solution of $1000 \mathrm{mg} \mathrm{L}^{-1}$ of $\mathrm{Pb}^{2+}$ was prepared by dissolving $0.159 \mathrm{~g}$ of $\mathrm{Pb}\left(\mathrm{NO}_{3}\right)_{2}$ (Merck, Darmstadt, Germany) in $10 \mathrm{~mL}$ of concentrated $\mathrm{HNO}_{3}$ and diluted to $100 \mathrm{~mL}$ in a volumetric flask. The working solutions were prepared daily with suitable dilution of this stock solution. The solutions of nitric acid and sodium hydroxide (in the concentration range of $0.01-1.0 \mathrm{M}$ ) were used to adjust the $\mathrm{pH}$.

\subsection{Apparatus and instruments}

A flame atomic absorption spectrometer from GBC Company (Sidney, Australia), Model Savanta, equipped with a deuterium lamp and hollow-cathode lamp was used for determination of lead. Morphology of the synthesized nanocomposite adsorbent was characterized with a by field emission scanning electron microscopy (FESEM, TESCAN, MIRA III, Czech Republic) 
instrument. In addition, EDX (energy dispersive spectrometer) and (EMA) element mapping analysis for the surface components of the samples were analysed using EDX-MAP (FESEM, TESCAN, MIRA III, Czech Republic). The structure and size of prepared Pip@MGO was investigated by a transmission electron microscope (JEM-1011, Japan TEM, Zeiss-EM10C-80 KV). FT-IR spectra was recorded with a Fourier Transform Infrared spectrometer (Thermo Nicolet, AVATAR, USA) at room temperature in $\mathrm{KBr}$ pellets. Magnetic properties of produced nanocomposite were obtained by a vibrating sample magnetometer (VSM, Meghnatis Daghigh Kavir Co., Kashan, Iran). Thermogravimetric Analysis (TGA) was done using a TA Instruments analyzer (Q600, USA) by scanning to $800{ }^{\circ} \mathrm{C}$ with a heating rate of $10{ }^{\circ} \mathrm{C} \mathrm{min}-1$. An ultrasonic water bath (ALEX, power $170 \mathrm{~W}$ and frequency $32 \mathrm{kHz}$ ) was applied to disperse the of Pip@MGO nanocomposite adsorbent in the aqueous solutions. The $\mathrm{pH}$ adjustment of sample solutions were done with a Metrohm digital pH meter (632 moled, Switzerland, Swiss) with a combined glass electrode.

\subsection{Synthesis of Pip@MGO nanocomposite}

\subsubsection{Preparation of Graphene Oxide (GO)}

Graphene Oxide (GO) was prepared according to Hummers' method with some modifications. Accordingly, $1.0 \mathrm{~g}$ of graphite powder was added to $50 \mathrm{~mL}$ of $\mathrm{H}_{2} \mathrm{SO}_{4}(98 \%)$ in an ice bath. Afterwards, $\mathrm{KMnO}_{4}(2 \mathrm{~g})$ was added slowly. The addition should be in a way that the temperature does not exceed abruptly. After 2 hours of stirring below $10^{\circ} \mathrm{C}$, and 1 hour at 35 ${ }^{\circ} \mathrm{C} ; 50 \mathrm{~mL}$ of deionized water was added. The mixture is heated at $85{ }^{\circ} \mathrm{C}$ for 1 hour. Then 10 $\mathrm{mL}$ of $\mathrm{H}_{2} \mathrm{O}_{2}(30 \%)$ was added in which the solution turned bright yellow. The mixture was filtered and was washed with $\mathrm{HCl}(5 \%)$ and deionized water for several times. Finally the obtained GO was dried at $60{ }^{\circ} \mathrm{C}$ in oven for 24 hours ${ }^{25}$. 


\subsubsection{Preparation of Magnetic Graphene Oxide (MGO)}

In a $250 \mathrm{~mL}$ round-bottom flask, $0.5 \mathrm{~g}$ of $\mathrm{GO}$ was added to deionized water $(100 \mathrm{~mL})$ and it was sonicated for 15 minutes. Subsequently, in another flask, $\mathrm{FeCl}_{3} \cdot 6 \mathrm{H}_{2} \mathrm{O}$ (1 g) and $\mathrm{FeCl}_{2} .4 \mathrm{H}_{2} \mathrm{O}(0.4 \mathrm{~g})$ were mixed totally in deionized water $(50 \mathrm{~mL})$, for 1 hour at $80{ }^{\circ} \mathrm{C}$. The flask containing GO was added to the solution of $\mathrm{Fe}(\mathrm{III}) / \mathrm{Fe}(\mathrm{II})$ and then sonicated for 30 minutes in sonication bath. The mixture was heated to $80{ }^{\circ} \mathrm{C}$ and after 30 minutes, $15 \mathrm{~mL}$ of ammonia (30\%) was added to it, resulted in MGO. The mixture was stirred for another 30 minutes and MGO was separated with an external magnet. The MGO was washed several times with deionized water and finally the obtained MGO was dried at $60{ }^{\circ} \mathrm{C}$ in oven for 24 hours.

\subsubsection{Preparation of piperazine modified Magnetic Graphene Oxide (Pip@MGO)}

In a $100 \mathrm{~mL}$ round bottom flask, $0.5 \mathrm{~g}$ of MGO was added to $50 \mathrm{ml}$ of toluene and the mixture was sonicated for 15 minutes. In another flask, 3-chloropropyltriethoxysilane (1 mmol, $0.24 \mathrm{~g})$ and piperazine ( $1 \mathrm{mmol}, 0.09 \mathrm{~g}$ ) was premixed in $20 \mathrm{~mL}$ of toluene for 1 hour at roomtemperature. The latter flask was added to MGO containing flask and the mixture was refluxed for 24 hours. Afterwards, Pip@ MGO was separated with an external magnet and it was washed several times with ethanol. Finally, the collected Pip@MGO nanocomposite was dried at 60 ${ }^{\circ} \mathrm{C}$ in oven for 24 hours and stored.

\subsection{Collection of real samples}

Four water samples including river water of Arvand Rud and Bahmanshir (Khuzestan Province, southwest of Iran), Persian Gulf seawater (Mahshahr, Khuzestan Province, Iran) and petrochemical wastewater sample (Abadan Petrochemical Company, Khuzestan Province, Iran) were collected in amber glass containers, which were previously pre-cleaned and acid- 
washed, and filtered through filter paper (Whatman, No. 1 Quantitative Filter Papers, $110 \mathrm{~mm}$ ). Then, the treated samples were stored at $4^{\circ} \mathrm{C}$ in the dark until analysis.

\subsection{General procedures}

In order to adsorb of $\mathrm{Pb}(\mathrm{II})$ ions on the Pip@MGO nanocomposite, a batch method was used. According to response surface methodology, 30 experiments were done and the influence of effective parameters, including solution $\mathrm{pH}$, initial concentration of $\mathrm{Pb}(\mathrm{II})$, adsorbent dosage and contact time were investigated on the lead removal efficiency. Briefly, $10 \mathrm{~mL}$ of solution containing different concentrations of lead at a given $\mathrm{pH}$ (in the range of 5-7) was transferred to the test tubes and the known weight of adsorbent was added and sonicated in an ultrasonic bath for $2 \mathrm{~min}$, then shacked (at $200 \mathrm{rpm}$ ) for a certain period of time, using an incubator shaker. After contact time, the liquid and solid phases were separated by an external magnet and the residual $\mathrm{Pb}^{2+}$ concentration was measured by FAAS. The removal percentage $(\% \mathrm{R})$ and adsorption capacity of $\mathrm{Pb}(\mathrm{II})$ ions $\left(\mathrm{q}_{\mathrm{e}} ; \mathrm{mg} \mathrm{g}^{-1}\right)$ were determined by the Eqs. (1) \& (2):

$$
\begin{aligned}
& \% R=\frac{C_{0}-C_{e}}{C_{0}} \times 100 \\
& q_{e}=\frac{\left(C_{0}-C_{e}\right) V}{M}
\end{aligned}
$$

where $C_{o}$ is initial and $C_{e}$ is the final concentration of $\mathrm{Pb}(\mathrm{II})$ ions $\left(\mathrm{mg} \mathrm{L}^{-1}\right), \mathrm{V}(\mathrm{L})$ is the volume of solution and $\mathrm{M}(\mathrm{mg})$ is the mass of adsorbent.

\subsection{Experimental design}

Response surface methodology (RSM) is a well-known and useful method that is widely used to optimize adsorption techniques and experimental design, modeling in chemical reactions and industrial processes ${ }^{26}$. In this work, the central composite design (CCD) under RSM was applied for designing the experiments. Therefore, the effect of four independent variables, 
including $\mathrm{pH}$ (in the range of 5-7), initial concentration of lead (in the range of 5-25 $\mathrm{mg} \mathrm{L}^{-1}$ ), adsorbent dosage (in the range of 1-13 mg) and contact time (in the range of 2.5-52.5 min) on the $\mathrm{Pb}(\mathrm{II})$ removal efficiency $(\% \mathrm{R})$ were investigated. The statistical software Design Expert (Version 11.0.3.0), Stat-Ease, Inc. was applied to analyze the experimental data. As shown in Table 1 , for four independent factors at 5 levels $(-\alpha,-1,0,1,+\alpha)$ thirty runs were designed, including six repeated runs for a central point, eight axial runs and 16 full factorial runs.

In this study, the proposed model was determined and confirmed by analysis of variance (ANOVA). In addition, $\mathrm{R}^{2}$, predicted $\mathrm{R}^{2}$, adjusted $\mathrm{R}^{2}$ and $\mathrm{F}$-test values were performed to evaluate and express the quality of the produced models.

\section{Results and discussion}

\subsection{Characterization studies}

In the FT-IR spectrum of the Pip@MGO (Fig. 1(a)), the stretching vibration of C-H bonds of the graphene oxide (GO) is apparent in the $2928 \mathrm{~cm}^{-1}$. The hydroxyl groups and also carboxylic groups on the surface of the GO is obvious at $3443 \mathrm{~cm}^{-1}$. It should be mentioned that the F-O vibration is also seen at $580 \mathrm{~cm}^{-1}$. The stretching vibration of $\mathrm{C}=\mathrm{C}$ bonds of $\mathrm{GO}$ is apparent at $1635 \mathrm{~cm}^{-1}$. The $\mathrm{CH}_{2}$ bending vibration is located at $1456 \mathrm{~cm}^{-1}$ which can be attributed to the methylene groups of piperazine and also the propyl silane linker. The $\mathrm{Si}-\mathrm{O}$ vibration of the silane linker appear about 462, 1040 and $1117 \mathrm{~cm}^{-1}$.

Thermogravimetric analysis (TGA) diagram of Pip@MGO is presented in Fig. 1(b). The first weight loss from room-temperature to $250{ }^{\circ} \mathrm{C}$ is due to the removal of adsorbed moisture entrapped physically in the nanocomposite. The second weight loss occurs from $250-800^{\circ} \mathrm{C}$ which can be attributed to the breakdown of organic moieties from the nanocomposite. According to Fig. 1(c), the XRD pattern of the nanocomposite clearly shows the characteristic 
$2 \theta$ peaks of $\mathrm{Fe}_{3} \mathrm{O}_{4}$ at $30.2^{\circ}, 35.52^{\circ}, 43.5^{\circ}, 54,57^{\circ}$ and $63^{\circ}$ are attributed to the crystal planes of magnetite at $220,311,400,422,511$ and 440 , respectively ${ }^{27}$.

The VSM curve of produced adsorbent is presented in Fig. 1(d). The results demonstrate that the nanocomposite contains magnetite nanoparticles which are super paramagnetic and the highest saturation magnetization is at $27.9 \mathrm{emu} / \mathrm{g}$. It is apparent from the magnetization that the nanocomposite is sufficiently magnetic to be easily separable via an external magnet.

The SEM images of the nanocomposite at two different magnifications has been recorded. According to the Fig. 2, the layered character of the graphene oxide and also the magnetite nanoparticles are easily observed. The nanoparticles are agglomerated to some extent, but they have been distributed on the whole surface of the graphene oxide. In addition, Fig. 3(a) shows the distribution of elements in the specified area by EDX mapping. It can be seen that nitrogen as a constituent of the piperazine group has been distributed uniformly all over the specific area which is an indication of the even functionalization of the whole surface without any accumulation. Fig. 3(b) illustrates the results of energy-dispersive X-ray spectrum (EDX) analysis of Pip@MGO. This data indicates the approximate chemical composition and confirms successful immobilization of piperazine which contains nitrogen. The iron is also present in the analysis due to the presence of $\mathrm{Fe}_{3} \mathrm{O}_{4}$ nanoparticles in the nanocomposite.

TEM images of the Pip@MGO nanocomposite is illustrated in Fig. 4. The layered 2D character of the graphene oxide is beautifully viewed in the TEM image which contains the magnetite nanoparticles located on its surface.

\subsection{Optimization by RSM}

To achieve maximum lead removal efficiency, the effect of four independent parameters including solution $\mathrm{pH}(\mathrm{A}), \mathrm{Pb}^{2+}$ concentration (B), adsorption dosage (C) and shaking time (D) was performed via RSM design based CCD experiments. According to the obtained data, the 
quadratic model equation was used to describe the relationship between the removal efficiency $(\% \mathrm{R})$ and the effective parameters as well as the interaction of operating parameters. This model is expressed in according with equation 1 as follows, in terms of coded factors:

$\% \mathrm{R}=+96.28-4.08 \mathrm{~A}-4.037 \mathrm{~B}+6.48 \mathrm{C}+12.99 \mathrm{D}+6.29 \mathrm{AC}-6.86 \mathrm{AD}-1.94 \mathrm{BD}+8.12 \mathrm{CD}$ $-20.30 A^{2}-6.41 B^{2}-13.99 C_{2}-9.33 D^{2}$

The ANOVA results for the removal efficiency of $\mathrm{Pb}(\mathrm{II})$ is summarized in Table 2 . As shown, the F-value was 228.36 and p-value was less than $0.05(\mathrm{p}<0.0001)$, therefore implies that the quadratic model was statistically significant. Based on this concept $(\mathrm{p}<0.05)$ factors of $\mathrm{A}, \mathrm{B}$, $\mathrm{C}, \mathrm{D}, \mathrm{AC}, \mathrm{AD}, \mathrm{BD}, \mathrm{CD}, \mathrm{A}^{2}, \mathrm{~B}^{2}, \mathrm{C}^{2}$ and $\mathrm{D}^{2}$ are significant model terms on removal efficiency of $\mathrm{Pb}$ (II) ions. In addition, the Lack of fit $\mathrm{P}$-value (0.2516) represented the LOF is not significantly relative to the pure error. The fit of proposed model was evaluated using coefficient of determination $\mathrm{R}^{2}(0.9938)$ and adjusted $\mathrm{R}^{2}(0.9895)$, which indicate a good relationship between the actual (experimentally observed) values and values predicted by the model, and the predicted- $\mathrm{R}^{2}(0.9777)$ showed that the model had a high potential to predict the response.

Three-dimensional (3D) surface plots, which obtained using the CCD design, are given in Fig. 2. By applying these 3D diagrams, the simultaneous effects of independent parameters and their interaction on the removal efficiency can be investigated.

The initial $\mathrm{pH}$ of lead ion solution is one of the significant factor affecting the removal efficiency. As can be seen from Fig. 5( $\mathrm{a}$ and b), the maximum removal efficiency of $\mathrm{Pb}$ (II) was achieved at $\mathrm{pH}$ 6.0. It can be explained that; at low $\mathrm{pH}$ values, due to presence of excessive amounts of $\mathrm{H}^{+}$ions in the lead solution, competition occurs in the active sites on the adsorbent surface and thus the removal efficiency decreased. However, at high $\mathrm{pH}$ values, despite the increase in de-protonation of adsorbent surface, $\mathrm{Pb}(\mathrm{II})$ ions are converted to hydroxide form and affect the absorption process, eventually reducing the removal efficiency. Fig. 5(a and d) 
shows that increasing the adsorbent dose increases the removal of ions, because it increases the number of adsorbent active sites and enhances the distribution coefficient of $\mathrm{Pb}(\mathrm{II})$ solution ${ }^{4}$. It is clear that, the optimum adsorbent dose for $\mathrm{Pb}^{2+}$ removal is in the range of $6-8 \mathrm{mg}$ of Pip@MGO nanocomposite.

The results of Fig. 5(b and d) indicate that the removal efficiency increases with increasing contact time between lead ion and adsorbent, and after 25 minutes the removal percentage reaches more than $90 \%$. As it is observed in Fig. 5(c), the removal efficiency decreased on increasing lead (II) concentration. It can be said that at higher concentration levels, because the adsorbent active sites are saturated with lead ions, the adsorption did not changed and the adsorption performance is decreased. As a result of experimental investigations, in the concentration range of $14-16 \mathrm{mg} \mathrm{L}^{-1}$ of $\mathrm{Pb}^{2+}$ and in the constant amount of absorbent dosage, the removal process was reached to equilibrium.

The maximum removal efficiency of lead was obtained at the optimum value of each independent parameter determined by RSM. The optimal experimental conditions were $\mathrm{pH}, 6$; initial concentration of $\mathrm{Pb}(\mathrm{II}), 15 \mathrm{mg} \mathrm{L}^{-1}$; adsorbent dosage, $7 \mathrm{mg}$; and contact time, $27.5 \mathrm{~min}$. The desirability function value under the optimum conditions was found to be 1 , which indicate the accuracy of the RSM divination.

\subsection{Adsorption experiments study}

In order to find the adsorption mechanism of lead ions on the Pip@MGO nanocomposite, the experimental data and homogeneity or heterogeneity of adsorbent were analysed by adsorption isothermal models. There are many isotherm models in the literature to describe the analyte adsorption on the adsorbents, however, in the present study, three conventional models including Freundlich, Langmuir and Temikin isotherm equations were used ${ }^{28}$. For this purpose, in batch mode; $0.01 \mathrm{~g}$ of Pip@MGO nanocomposite was added to $10 \mathrm{~mL}$ of 
$\mathrm{Pb}^{2+}$ solution with initial concentrations range of $50-600 \mathrm{mg} \mathrm{L}^{-1}$, which was stabilized in $\mathrm{pH}=6.0$, and shacked $(200 \mathrm{rpm})$ for $60 \mathrm{~min}$ at $25^{\circ} \mathrm{C}$. Subsequently, the magnetic adsorbent was isolated and the lead equilibrium concentration of each experiment was determined by FAAS, and the experimental data were adjusted with the mentioned isotherm models.

In the Langmuir model, it is assumed that the adsorption is monolayer and occurs at a homogeneous surface, without interaction between the absorbed materials ${ }^{29}$. The linearity of the Langmuir model is described by the equation (2) as follows:

$\frac{C_{e}}{q_{e}}=\frac{1}{K_{L} q_{\max }}+\frac{C_{e}}{q_{\max }}$

where, $C_{\mathrm{e}}\left(\mathrm{mg} \mathrm{L}^{-1}\right)$ and $q_{e}\left(\mathrm{mg} \mathrm{g}^{-1}\right)$ are $\mathrm{Pb}(\mathrm{II})$ ion concentration and quantity of lead ions adsorbed onto the absorbent surface at equilibrium, $q_{\max }\left(\mathrm{mg} \mathrm{g}^{-1}\right)$ is the maximum adsorption capacity and $K_{L}\left(\mathrm{~mL} \mathrm{mg}^{-1}\right)$ is the Langmuir adsorption equilibrium constant. $q_{\max }$ and $K_{L}$ could be calculated with a straight line drawn from of $C_{e} / q_{e}$ versus $C_{e}$.

The Freundlich isotherm is not accept the capacity of one layer and is based on the assumption of adsorption on heterogeneous surfaces, due to the increase in the amount of analyte adsorbed in the solution ${ }^{30}$. This model is linear by the equation (3) as follows:

$\log q_{e}=\log k_{f}+\left(\frac{1}{n}\right) \log C_{e}$

where, $n$ and $K_{F}\left(\mathrm{mg} \mathrm{g}^{-1}\left(\mathrm{~L} \mathrm{mg}^{-1}\right)^{1 / n}\right)$ are Freundlich constants, which are related to the heterogeneity factor and adsorption capacity, respectively. These constants can be calculated by plotting of $\log q_{e}$ versus $\log C_{e}$. The $n$ value should be in the range 1 to 10 for favorable adsorption process.

The Temkin isotherm model contains a parameter which considers the adsorbent-adsorbate interactions and assumes that the adsorption heat decline linearly with the surface covered 
between the adsorbates and adsorbent ${ }^{31}$. The linearity of Temkin model is given by equation (4):

$q_{e}=B \ln K_{T}+\left(\frac{R T}{b}\right) \ln C_{e}$

where, $B=R T / b_{T}, b_{T}\left(\mathrm{~J} \mathrm{~mol}^{-1}\right)$ is the constant of Temkin that is related to the heat of adsorption, $K_{T}\left(\mathrm{~L} \mathrm{~g} \mathrm{~g}^{-1}\right)$ is the equilibrium binding constant, $R$ and $T$ are the gas constant $\left(8.3145 \mathrm{~J} \mathrm{~mol}^{-1} \mathrm{~K}^{-}\right.$ ${ }^{1}$ ) and absolute temperature in Kelvin, respectively. The $B$ and $K_{T}$ values can be calculated from slope and intercept of a graph between $q_{e}$ and $\ln C_{e}$.

The Langmuir, Freundlich and Temkin parameters for the lead ions adsorption onto the Pip@MGO nanocomposite were listed in Table 3. As can be seen, the higher value of $\mathrm{R}^{2}$ (0.996) for Langmuir model, compared to other models, indicates the suitability of the adsorption data and correlation of the $\mathrm{Pb}$ (II) monolayer adsorption on homogeneous surface of the nanocomposite adsorbent. The maximum adsorption capacity $\left(q_{\max }\right)$ of Pip@MGO nanocomposite for $\mathrm{Pb}(\mathrm{II})$ is $558.2 \mathrm{mg} \mathrm{g}^{-1}$ and it helps the fact that the proposed adsorbent has a high surface area, especially in the nano proportions.

\subsection{Adsorption kinetics study}

The kinetic study of the adsorption process provides information on the adsorption mechanism and how the $\mathrm{Pb}(\mathrm{II})$ ions are transferred from the liquid phase to the solid phase. Therefore, two kinetic models, including pseudo-first-order and pseudo-second-order equations were applied to fit the experimental data. These experiments were performed by shaking $0.01 \mathrm{~g}$ of Pip@MGO nanocomposite in $10 \mathrm{~mL}$ solution of $10 \mathrm{mg} \mathrm{L}^{-1} \mathrm{~Pb}(\mathrm{II})$ at $\mathrm{pH} 6$ for $2,3,5,10,30$ and $90 \mathrm{~min}$. The linearized forms of pseudo-first-order and pseudo-second-order models ${ }^{32}$ are as equation (5) and (6), respectively:

$\ln \left(q_{e}-q_{t}\right)=\ln q_{e}-K_{1} t$ 


$$
\frac{\mathrm{t}}{q_{t}}=\frac{1}{k_{2} q_{e}^{2}}+\frac{1}{q_{e}}
$$

where, $q_{e}$ and $q_{t}$ are the adsorbed amount of $\mathrm{Pb}(\mathrm{II})$ ions at equilibrium and time $\mathrm{t}\left(\mathrm{mg} \mathrm{g}^{-1}\right)$, respectively. $k_{1}\left(\mathrm{~min}^{-1}\right)$ and $k_{2}\left(\mathrm{~g} \mathrm{mg}^{-1} \mathrm{~min}^{-1}\right)$ are the rate constant of pseudo- $1^{\text {st }}$ and $2^{\text {nd }}$ order, respectively. The constants of $k_{1}$ and $k_{2}$ can be calculated by plotting of equation (5) and (6).

The data obtained from the two kinetic models are shown in Table 4. According to these data, a comparison of the correlation coefficient values for both models shows that $\mathrm{R}^{2}(0.994)$ for the pseudo-second-order is greater than $\mathrm{R}^{2}(0.724)$ for the pseudo-first-order, therefore it expresses the good fitting of the experimental data with this model.

\subsection{Applications and reusability}

In order to evaluate the application of the proposed method in the removing lead ions from real samples, three different water and wastewater samples, including Arvand Rud and Bahmanshir rivers, Persian Gulf seawater and petrochemical wastewater samples were investigated. To examine the effect of the sample matrices on the removal process, all samples were spiked by known concentrations of $\mathrm{Pb}(\mathrm{II})$ ions at two levels, 5 and $10 \mathrm{mg} \mathrm{L}^{-1}$, subsequently the suggested method was performed under optimum conditions. The analysis results of each sample along with the recoveries are presented in Table 5. As can be seen, the removal efficiency of the lead ions in the studied samples were upper $93 \%$ which show well suitability of the developed nanocpmposite adsorbent for removing of $\mathrm{Pb}(\mathrm{II})$ ions in various real samples.

The regeneration cycles of Pip@MGO nanocomposite were carried out using acidic solution. The adsorption/desorption study proved that the adsorbent with nitric acid (1 M) could be reused for four cycles. The removal efficiency of Pip@MGO nanocomposite for lead decreased to $90 \%$ after mentioned cycles.

\subsection{Comparison to methods in literature}


A comparative study of the analytical results of $\mathrm{Pb}(\mathrm{II})$ adsorption on the Pip@MGO nanocomposite with other adsorbents in the literature is reported in Table 6. From this table, it is obvious that Pip@MGO nanocomposite has a good adsorption capacity $\left(\mathrm{mg} \mathrm{g}^{-1}\right)$ for lead uptake compared to most mentioned adsorbents, while the adsorbent dosage used is less or comparable to other adsorbents.

\section{Conclusions}

In this present study, we have constructed a new magnetic graphene oxide-functionalized piperazine (Pip@MGO) nanocomposite to remove $\mathrm{Pb}$ (II) ions from contaminated waters. The synthesized nanocomposite adsorbent was analyzed by using XRD, FESEM, TEM, EDX, TGA, VSM and FT-IR techniques. The influence of four key parameters consisting initial $\mathrm{pH}$, adsorbent dosage, initial concentration of lead and contact time on the removal efficiency were evaluated by RSM based on the central composite design (CCD) model. As a result of mathematical optimization, the maximum adsorption efficiency was obtained at $\mathrm{pH}$ 6.0, adsorbent dose of $7 \mathrm{mg}$, initial $\mathrm{Pb}^{2+}$ concentration of $15 \mathrm{mg} \mathrm{L}^{-1}$ and contact time of $10 \mathrm{~min}$.

The isotherm studies indicated that lead adsorption equilibrium data were more appropriate with Langmuir isotherm model. In addition, the obtained equilibrium data were applied to the kinetic equations and found to be consistent with the pseudo-second order model for lead adsorption. The suggested nanocomposite adsorbent represented good adsorption capacity and could be regenerated by nitric acid and reused for up to four adsorption-desorption cycles. According to our findings, the Pip@MGO nanocomposite as an effective adsorbent can be successfully used for the removal of $\mathrm{Pb}(\mathrm{II})$ ions from different real samples and changes in the sample matrices do not have a significant effect on the removal efficiency of the proposed methodology. 


\section{Acknowledgement}

The authors greatly appreciate the financial support of this work by Khorramshahr University of Marine Science and Technology Research Council.

\section{Data Availability}

All data generated or analysed during this study are included in this published article.

\section{References}

1 Zaferani, S. P. G., Emami, M. R. S., Amiri, M. K. \& Binaeian, E. Optimization of the removal $\mathrm{Pb}$ (II) and its Gibbs free energy by thiosemicarbazide modified chitosan using RSM and ANN modeling. International Journal of Biological Macromolecules 139, 307-319, doi:https://doi.org/10.1016/j.ijbiomac.2019.07.208 (2019).

2 Gutiérrez-López, D., Flores-Alamo, N., Carreño-de-León, M. \& Solache-Rios, M. Removal of $\mathrm{Pb}$ (II) from aqueous solution by using micro-spheres of Zea mays rachissodium alginate by batch and column systems. Water Supply 20, 2133-2144 (2020).

3 Kaur, M., Kumari, S. \& Sharma, P. Removal of Pb (II) from aqueous solution using nanoadsorbent of Oryza sativa husk: Isotherm, kinetic and thermodynamic studies. Biotechnology Reports 25, e00410, doi:https://doi.org/10.1016/j.btre.2019.e00410 (2020).

4 Şahan, T. Application of RSM for $\mathrm{Pb}$ (II) and $\mathrm{Cu}(\mathrm{II})$ adsorption by bentonite enriched with SH groups and a binary system study. Journal of Water Process Engineering 31, 100867, doi:https://doi.org/10.1016/j.jwpe.2019.100867 (2019).

5 Tao, Y., Zhang, C., Lü, T. \& Zhao, H. Removal of Pb (II) Ions from Wastewater by Using Polyethyleneimine-Functionalized Fe3O4 Magnetic Nanoparticles. Applied Sciences 10, 948 (2020).

6 Motlochová, M., Slovák, V., Pližingrová, E., Lidin, S. \& Šubrt, J. Highly-efficient removal of $\mathrm{Pb}$ (ii), $\mathrm{Cu}$ (ii) and $\mathrm{Cd}$ (ii) from water by novel lithium, sodium and potassium titanate reusable microrods. RSC Advances 10, 3694-3704, doi:10.1039/C9RA08737K (2020).

7 Moradi, A., Najafi Moghadam, P., Hasanzadeh, R. \& Sillanpää, M. Chelating magnetic nanocomposite for the rapid removal of $\mathrm{Pb}$ (ii) ions from aqueous solutions: characterization, kinetic, isotherm and thermodynamic studies. RSC Advances 7, 433448, doi:10.1039/C6RA26356A (2017).

8 Tran, C. V., Quang, D. V., Nguyen Thi, H. P., Truong, T. N. \& La, D. D. Effective Removal of $\mathrm{Pb}(\mathrm{II})$ from Aqueous Media by a New Design of $\mathrm{Cu}-\mathrm{Mg}$ Binary Ferrite. ACS Omega 5, 7298-7306, doi:10.1021/acsomega.9b04126 (2020).

9 Ibrahim, H. S., Ammar, N. S., Soylak, M. \& Ibrahim, M. Removal of Cd(II) and Pb(II) from aqueous solution using dried water hyacinth as a biosorbent. Spectrochimica Acta Part A: Molecular and Biomolecular Spectroscopy 96, 413-420, doi:https://doi.org/10.1016/j.saa.2012.05.039 (2012). 
10 Bhatnagar, A. \& Sillanpää, M. Removal of natural organic matter (NOM) and its constituents from water by adsorption - A review. Chemosphere 166, 497-510, doi:https://doi.org/10.1016/j.chemosphere.2016.09.098 (2017).

11 Memon, Z. M., Yilmaz, E. \& Soylak, M. One step hydrothermal synthesis and characterization of moss like MWCNT-Bi2S3 nanomaterial for solid phase extraction of copper. Talanta 174, 645-651, doi:https://doi.org/10.1016/j.talanta.2017.06.068 (2017).

12 Sadegh, H. et al. The role of nanomaterials as effective adsorbents and their applications in wastewater treatment. Journal of Nanostructure in Chemistry 7, 1-14, doi:10.1007/s40097-017-0219-4 (2017).

13 Makvandi, P. et al. Functionalization of polymers and nanomaterials for water treatment, food packaging, textile and biomedical applications: a review. Environmental Chemistry Letters 19, 583-611, doi:10.1007/s10311-020-01089-4 (2021).

14 Zahedi, S. S., Larki, A., Saghanezhad, S. J. \& Nikpour, Y. 1,4-Diazabicyclo [2.2.2] Octane Functionalized Mesoporous Silica SBA-15 (SBA-15@DABCO): a Novel Highly Selective Adsorbent for Selective Separation/Preconcentration of Cr(VI) from Environmental Water Samples. Silicon, doi:10.1007/s12633-020-00903-6 (2021).

15 Rahmi, Ishmaturrahmi \& Mustafa, I. Methylene blue removal from water using H2SO4 crosslinked magnetic chitosan nanocomposite beads. Microchemical Journal 144, 397402, doi:https://doi.org/10.1016/j.microc.2018.09.032 (2019).

16 Yuvali, D., Narin, I., Soylak, M. \& Yilmaz, E. Green synthesis of magnetic carbon nanodot/graphene oxide hybrid material (Fe3O4@C-nanodot@ GO) for magnetic solid phase extraction of ibuprofen in human blood samples prior to HPLC-DAD determination. Journal of Pharmaceutical and Biomedical Analysis 179, 113001, doi:https://doi.org/10.1016/j.jpba.2019.113001 (2020).

17 Yilmaz, E., Ulusoy, H. İ., Demir, Ö. \& Soylak, M. A new magnetic nanodiamond/graphene oxide hybrid (Fe3O4@ND@GO) material for preconcentration and sensitive determination of sildenafil in alleged herbal aphrodisiacs by HPLC-DAD system. Journal of Chromatography $B$ 1084, 113-121, doi:https://doi.org/10.1016/j.jchromb.2018.03.030 (2018).

18 Yusuf, M., Kumar, M., Khan, M. A., Sillanpää, M. \& Arafat, H. A review on exfoliation, characterization, environmental and energy applications of graphene and graphene-based composites. Advances in Colloid and Interface Science 273, 102036, doi:https://doi.org/10.1016/j.cis.2019.102036 (2019).

19 Ozkantar, N., Yilmaz, E., Soylak, M. \& Tuzen, M. Pyrocatechol violet impregnated magnetic graphene oxide for magnetic solid phase microextraction of copper in water, black tea and diet supplements. Food Chemistry 321, 126737, doi:https://doi.org/10.1016/j.foodchem.2020.126737 (2020).

20 Guo, T. et al. Mechanism of $\mathrm{Cd}$ (II) and $\mathrm{Cu}$ (II) Adsorption onto Few-Layered Magnetic Graphene Oxide as an Efficient Adsorbent. ACS Omega 6, 16535-16545, doi:10.1021/acsomega.1c01770 (2021).

21 Li, N., Qiu, J. \& Qian, Y. Polyethyleneimine-modified magnetic carbon nanotubes as solid-phase extraction adsorbent for the analysis of multi-class mycotoxins in milk via liquid chromatography-tandem mass spectrometry. Journal of Separation Science 44, 636-644, doi:https://doi.org/10.1002/jssc.202000821 (2021).

22 Liang, W., Lu, Y., Li, N., Li, H. \& Zhu, F. Microwave-assisted synthesis of magnetic surface molecular imprinted polymer for adsorption and solid phase extraction of 4nitrophenol in wastewater. Microchemical Journal 159, 105316, doi:https://doi.org/10.1016/j.microc.2020.105316 (2020). 
23 Yilmaz, E., Alosmanov, R. M. \& Soylak, M. Magnetic solid phase extraction of lead(ii) and cadmium(ii) on a magnetic phosphorus-containing polymer (M-PhCP) for their microsampling flame atomic absorption spectrometric determinations. RSC Advances 5, 33801-33808, doi:10.1039/C5RA02328A (2015).

24 Huang, T. et al. Efficient removal of methylene blue from aqueous solutions using magnetic graphene oxide modified zeolite. Journal of Colloid and Interface Science 543, 43-51, doi:https://doi.org/10.1016/j.jcis.2019.02.030 (2019).

25 Doustkhah, E. \& Rostamnia, S. Covalently bonded sulfonic acid magnetic graphene oxide: Fe3O4@GO-Pr-SO3H as a powerful hybrid catalyst for synthesis of indazolophthalazinetriones. Journal of Colloid and Interface Science 478, 280-287, doi:https://doi.org/10.1016/j.jcis.2016.06.020 (2016).

26 Nasiri, R., Arsalani, N. \& Panahian, Y. One-pot synthesis of novel magnetic threedimensional graphene/chitosan/nickel ferrite nanocomposite for lead ions removal from aqueous solution: RSM modelling design. Journal of Cleaner Production 201, 507515, doi:https://doi.org/10.1016/j.jclepro.2018.08.059 (2018).

27 Raghu, M. S. et al. Adsorption and antimicrobial studies of chemically bonded magnetic graphene oxide-Fe3O4 nanocomposite for water purification. Journal of Water Process Engineering 17, 22-31, doi:https://doi.org/10.1016/j.jwpe.2017.03.001 (2017).

28 Tamoradi Babaei, Z., Larki, A. \& Ghanemi, K. Application of molybdenum disulfide nanosheets adsorbent for simultaneous preconcentration and determination of $\mathrm{Cd}(\mathrm{II})$, $\mathrm{Pb}(\mathrm{II}), \mathrm{Zn}(\mathrm{II})$ and $\mathrm{Ni}(\mathrm{II})$ in water samples. Journal of the Iranian Chemical Society, doi:10.1007/s13738-021-02289-7 (2021).

29 Javinezhad, S., Larki, A., Nikpour, Y. \& Saghanezhad, S. J. Study on the Application of Cucurbit[6]uril as a Nanoporous Adsorbent for the Removal of 2,4-Dinitrophenol from Wastewaters Analytical and Bioanalytical Chemistry Research 5, 217-228, doi:10.22036/abcr.2018.113797.1180 (2018).

30 Shiralipour, R. \& Larki, A. Pre-concentration and determination of tartrazine dye from aqueous solutions using modified cellulose nanosponges. Ecotoxicology and Environmental Safety 135, 123-129, doi:https://doi.org/10.1016/j.ecoenv.2016.09.038 (2017).

31 Pourreza, N., Parham, H. \& Pourbati, M. A. Magnetic iron oxide nanoparticles modified by methyl trioctyl ammonium chloride as an adsorbent for the removal of erythrosine from aqueous solutions. Desalination and Water Treatment 57, 1745417462, doi:10.1080/19443994.2015.1086892 (2016).

32 Tuzen, M., Sari, A., Mendil, D. \& Soylak, M. Biosorptive removal of mercury(II) from aqueous solution using lichen (Xanthoparmelia conspersa) biomass: Kinetic and equilibrium studies. Journal of Hazardous Materials 169, 263-270, doi:https://doi.org/10.1016/j.jhazmat.2009.03.096 (2009).

33 Cui, L. et al. EDTA functionalized magnetic graphene oxide for removal of $\mathrm{Pb}(\mathrm{II})$, $\mathrm{Hg}$ (II) and $\mathrm{Cu}(\mathrm{II})$ in water treatment: Adsorption mechanism and separation property. Chemical Engineering Journal 281, 1-10, doi:https://doi.org/10.1016/j.cej.2015.06.043 (2015).

34 Alipour, A., Zarinabadi, S., Azimi, A. \& Mirzaei, M. Adsorptive removal of $\mathrm{Pb}(\mathrm{II})$ ions from aqueous solutions by thiourea-functionalized magnetic $\mathrm{ZnO} /$ nanocellulose composite: Optimization by response surface methodology (RSM). International Journal of Biological Macromolecules 151, 124-135, doi:https://doi.org/10.1016/j.ijbiomac.2020.02.109 (2020).

35 Ghasemi, E., Heydari, A. \& Sillanpää, M. Superparamagnetic Fe3O4@EDTA nanoparticles as an efficient adsorbent for simultaneous removal of $\mathrm{Ag}(\mathrm{I}), \mathrm{Hg}(\mathrm{II})$, 
$\mathrm{Mn}(\mathrm{II}), \mathrm{Zn}(\mathrm{II}), \mathrm{Pb}(\mathrm{II})$ and $\mathrm{Cd}(\mathrm{II})$ from water and soil environmental samples. Microchemical Journal 131, 51-56, doi:https://doi.org/10.1016/j.microc.2016.11.011 (2017).

36 Lyu, F. et al. Efficient removal of $\mathrm{Pb}$ (II) ions from aqueous solution by modified red mud. Journal of Hazardous Materials 406, 124678, doi:https://doi.org/10.1016/j.jhazmat.2020.124678 (2021).

37 Behbahani, E. S., Dashtian, K. \& Ghaedi, M. Fe3O4-FeMoS4: Promise magnetite $\mathrm{LDH}$-based adsorbent for simultaneous removal of $\mathrm{Pb}$ (II), $\mathrm{Cd}$ (II), and $\mathrm{Cu}$ (II) heavy metal ions. Journal of Hazardous Materials 410, 124560, doi:https://doi.org/10.1016/j.jhazmat.2020.124560 (2021).

38 Ji, J., Chen, G. \& Zhao, J. Preparation and characterization of amino/thiol bifunctionalized magnetic nanoadsorbent and its application in rapid removal of $\mathrm{Pb}$ (II) from aqueous system. Journal of Hazardous Materials 368, 255-263, doi:https://doi.org/10.1016/j.jhazmat.2019.01.035 (2019).

39 Dai, K. et al. Judicious fabrication of bifunctionalized graphene oxide/MnFe2O4 magnetic nanohybrids for enhanced removal of $\mathrm{Pb}(\mathrm{II})$ from water. Journal of Colloid and Interface Science 579, 815-822, doi:https://doi.org/10.1016/j.jcis.2020.06.085 (2020). 
Table 1

Levels of the independent variables for CCD experiments.

\begin{tabular}{lccccccc}
\hline & & \multicolumn{5}{c}{ Coded levels } \\
Variables & Units & Type & \multicolumn{7}{c}{0} \\
\cline { 3 - 8 } & & & $-\alpha$ & -1 & 0 & +1 & $+\alpha$ \\
\hline Initial pH & - & $\mathrm{A}$ & 5 & 6 & 7 & 8 & 9 \\
Lead ions conc. & $\left(\mathrm{mg} \mathrm{L}^{-1}\right)$ & $\mathrm{B}$ & 5 & 10 & 15 & 20 & 25 \\
Adsorbent dosage & $(\mathrm{mg})$ & $\mathrm{C}$ & 1 & 4 & 7 & 10 & 13 \\
Time & $(\mathrm{min})$ & $\mathrm{D}$ & 2.5 & 15 & 27.5 & 40 & 52.5 \\
\hline
\end{tabular}


Table 2

ANOVA results for $\mathrm{Pb}(\mathrm{II})$ removal.

\begin{tabular}{|c|c|c|c|c|c|c|}
\hline Source & $\begin{array}{l}\text { Sum of } \\
\text { Squares }\end{array}$ & Df & $\begin{array}{l}\text { Mean } \\
\text { Square }\end{array}$ & F-Value & P-Value & \\
\hline Model & 22574.70 & 12 & 1881.23 & 228.36 & $<0.0001$ & significant \\
\hline A-pH & 276.76 & 1 & 276.76 & 33.60 & $<0.0001$ & \\
\hline B-Conc. & 356.51 & 1 & 356.51 & 43.28 & $<0.0001$ & \\
\hline C-Ads. Do. & 1046.76 & 1 & 1046.76 & 127.06 & $<0.0001$ & \\
\hline D-time & 3792.62 & 1 & 3792.62 & 460.38 & $<0.0001$ & \\
\hline $\mathrm{AC}$ & 577.20 & 1 & 577.20 & 70.07 & $<0.0001$ & \\
\hline $\mathrm{AD}$ & 601.48 & 1 & 601.48 & 73.01 & $<0.0001$ & \\
\hline $\mathrm{BD}$ & 42.58 & 1 & 42.58 & 5.17 & 0.0363 & \\
\hline $\mathrm{CD}$ & 1038.45 & 1 & 1038.45 & 126.06 & $<0.0001$ & \\
\hline $\mathrm{A}^{2}$ & 10940.59 & 1 & 10940.59 & 1328.05 & $<0.0001$ & \\
\hline $\mathrm{B}^{2}$ & 1126.77 & 1 & 1126.77 & 136.78 & $<0.0001$ & \\
\hline $\mathrm{C}^{2}$ & 5024.35 & 1 & 5024.35 & 609.89 & $<0.0001$ & \\
\hline $\mathrm{D}^{2}$ & 2158.91 & 1 & 2158.91 & 262.06 & $<0.0001$ & \\
\hline Residual & 140.05 & 17 & 8.24 & & & \\
\hline Lack of Fit & 114.63 & 12 & 9.55 & 1.88 & 0.2516 & not significant \\
\hline Pure Error & 25.42 & 5 & 5.08 & & & \\
\hline Cor Total & 22714.75 & 29 & & & & \\
\hline
\end{tabular}


Table 3

Isotherm parameters for the adsorption of $\mathrm{Pb}(\mathrm{II})$ ions onto Pip@MGO nanocomposite.

\begin{tabular}{llc}
\hline Isotherm & Parameters & Values of parameters \\
\hline \multirow{2}{*}{ Langmuir } & $R^{2}$ & 0.996 \\
& $K_{\mathrm{L}}\left(\mathrm{L} \mathrm{g}^{-1}\right)$ & 0.029 \\
& $q_{\mathrm{m}}\left(\mathrm{mg} \mathrm{g}^{-1}\right)$ & 558.2 \\
& $R_{\mathrm{L}}$ & $0.06-0.41$ \\
\hline \multirow{2}{*}{ Freundlich } & $R^{2}$ & 0.899 \\
& $K_{\mathrm{F}}\left(\mathrm{L} \mathrm{g}^{-1}\right)$ & 1.624 \\
& $n$ & 0.27 \\
\hline \multirow{3}{*}{ Temkin } & $R^{2}$ & 0.729 \\
& $A_{\mathrm{T}}\left(\mathrm{L} \mathrm{g}^{-1}\right)$ & 0.38 \\
& $b_{T}$ & 20.34 \\
& $B\left(\mathrm{~J} \mathrm{~mol}^{-1}\right)$ & 121.88 \\
\hline
\end{tabular}


Table 4

Kinetic parameters for the adsorption of $\mathrm{Pb}(\mathrm{II})$ ions with Pip@MGO nanocomposite.

\begin{tabular}{llc}
\hline Models & Parameters & Cd(II) \\
\hline \multirow{3}{*}{ Pseudo-1 } & $q_{\mathrm{e}}\left(\mathrm{mg} \mathrm{g}^{-1}\right)$ & 0.22 \\
& $k_{1}\left(\mathrm{~min}^{-1}\right)$ & -0.058 \\
& $R^{2}$ & 0.724 \\
\hline Pseudo-2 & $q_{\mathrm{e}}\left(\mathrm{mg} \mathrm{g}^{-1}\right)$ & 9.51 \\
& $K_{2}\left(\mathrm{~g} \mathrm{mg}^{-1} \mathrm{~min}^{-1}\right)$ & 0.049 \\
& $R^{2}$ & 0.994 \\
\hline
\end{tabular}


Table 5

Removal of $\mathrm{Pb}(\mathrm{II})$ from various water and wastewater samples using proposed method.

\begin{tabular}{lcc}
\hline Sample & $\begin{array}{c}\text { Add concentration } \\
\left(\mathbf{m g ~ L}^{-\mathbf{1}}\right)\end{array}$ & Removal (\%) \\
\hline River water (Karun) & 5 & $>99$ \\
& 10 & $>99$ \\
\hline River water (Bahmanshir) & 5 & $>99$ \\
& 10 & $>99$ \\
\hline Wastewater effluent & 5 & $>99$ \\
(Abadan Petrochemical Company) & 10 & $>99$ \\
\hline Seawater (Persian Gulf) & 5 & 93 \\
\hline
\end{tabular}




\section{Table 6}

Comparative study of adsorption capacity of Pip@MGO nanocomposite with different adsorbents for removal of $\mathrm{Pb}$ (II).

\begin{tabular}{|c|c|c|c|c|c|}
\hline Adsorbent & pH & $\begin{array}{l}\mathrm{qm} \\
\left(\mathrm{mg} \mathrm{g}^{-1}\right)\end{array}$ & $\begin{array}{l}\text { Equilibrium } \\
\text { time (min) }\end{array}$ & $\begin{array}{l}\text { Adsorbent } \\
\text { Dosage }(\mathrm{g} / \mathrm{L})\end{array}$ & Ref. \\
\hline Rice husk nanoadsorbent & 8 & 6.1 & 70 & 12 & 3 \\
\hline $\begin{array}{l}\text { Bentonite enriched-SH } \\
\text { groups }\end{array}$ & 5 & 12 & 146 & 1.5 & 4 \\
\hline $\begin{array}{l}\mathrm{Fe}_{3} \mathrm{O}_{4} @ \text { glycidylmethacrylate- } \\
\text { acrylamide }\end{array}$ & 6 & 158.7 & $10 \mathrm{~s}$ & 0.2 & 7 \\
\hline $\begin{array}{l}\text { GO nanocomposite decorated } \\
\text { with } \mathrm{NiFe}_{2} \mathrm{O}_{4} \text { nanoparticles }\end{array}$ & 8.5 & 957 & 18 & - & 26 \\
\hline EDTA-magnetic GO & 4.2 & 479 & 20 & - & 33 \\
\hline $\begin{array}{l}\text { Thiourea modified magnetic } \\
\mathrm{ZnO} / \text { nano Celloluse }\end{array}$ & 6.5 & 554.4 & 14.5 & 0.2 & 34 \\
\hline $\mathrm{Fe}_{3} \mathrm{O}_{4}$-EDTA & 7.9 & 112 & 10 & 1.1 & 35 \\
\hline Modified red mud & 5 & 551.1 & 60 & 1.0 & 36 \\
\hline $\mathrm{Fe}_{3} \mathrm{O}_{4} / \mathrm{FeMoS}_{4} / \mathrm{MgAl}-\mathrm{LDH}$ & 5 & 190.7 & 60 & 3.0 & 37 \\
\hline $\begin{array}{l}\text { Amino/thiol bifunctionalized } \\
\text { magnetic nanoparticle }\end{array}$ & 5 & 110.1 & 3 & 1.0 & 38 \\
\hline Bifunctionalized & 5.5 & 366.4 & 120 & - & 39 \\
\hline $\mathrm{GO} / \mathrm{MnFe}_{2} \mathrm{O}_{4}$ & & & & & \\
\hline Nanohybrids & & & & & \\
\hline Pip@MGO nanocomposite & 6 & 558.2 & 27.5 & 0.7 & $\begin{array}{c}\text { Present } \\
\text { work }\end{array}$ \\
\hline
\end{tabular}




\section{Figure Captions}

Fig. 1. (a) FT-IR spectrum, (b) TGA diagram, (c) XRD pattern and (d) VSM curve of Pip@MGO nanocomposite.

Fig. 2. SEM images of Pip@MGO.

Fig. 3. Elemental mapping of Pip@MGO.

Fig. 4. TEM image of the Pip@MGO.

Fig. 5. 3D response surface plots of $\mathrm{Pb}(\mathrm{II})$ adsorption on Pip@MGO nanocomposite. 


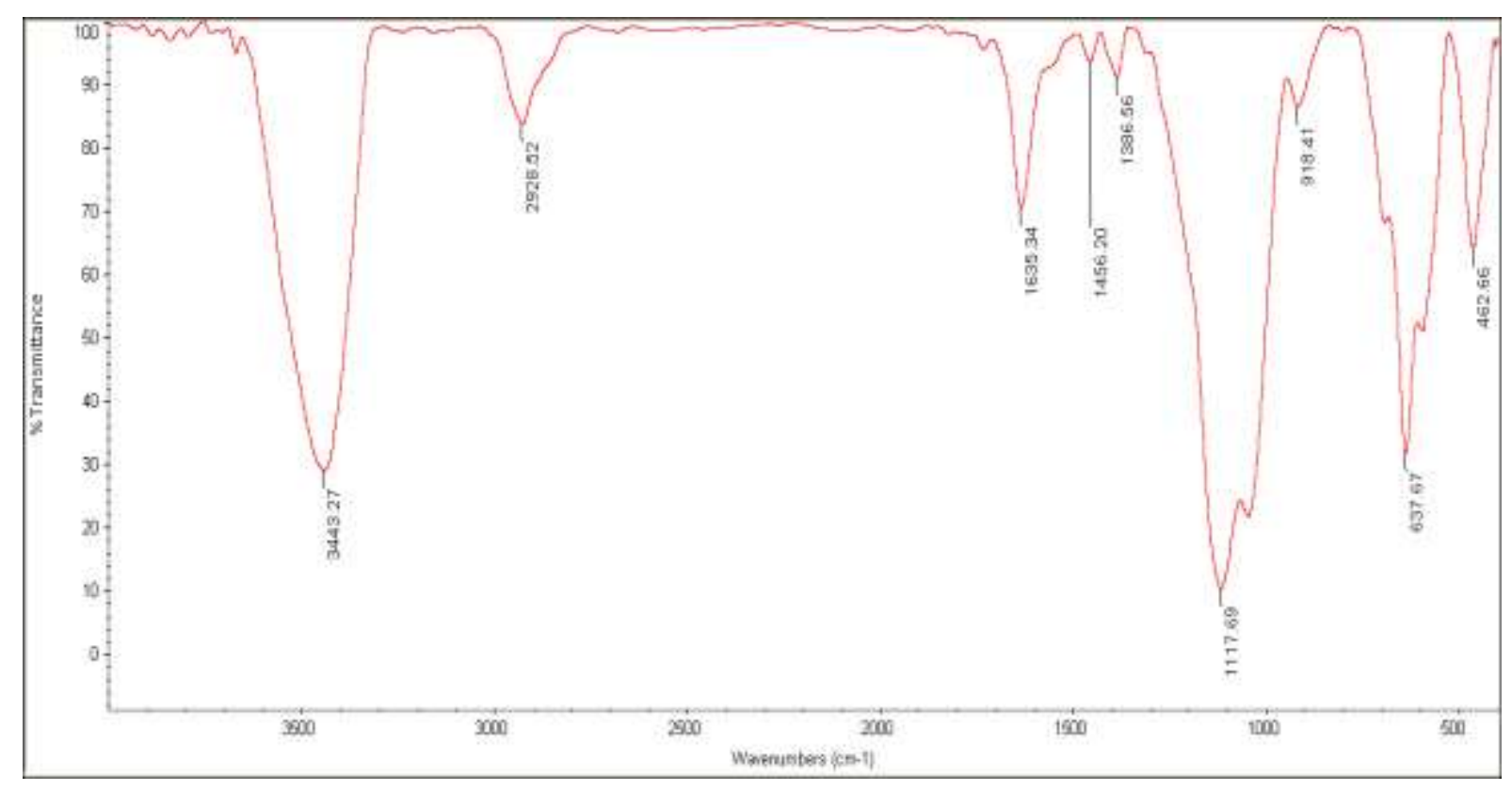

Fig. 1 (a)

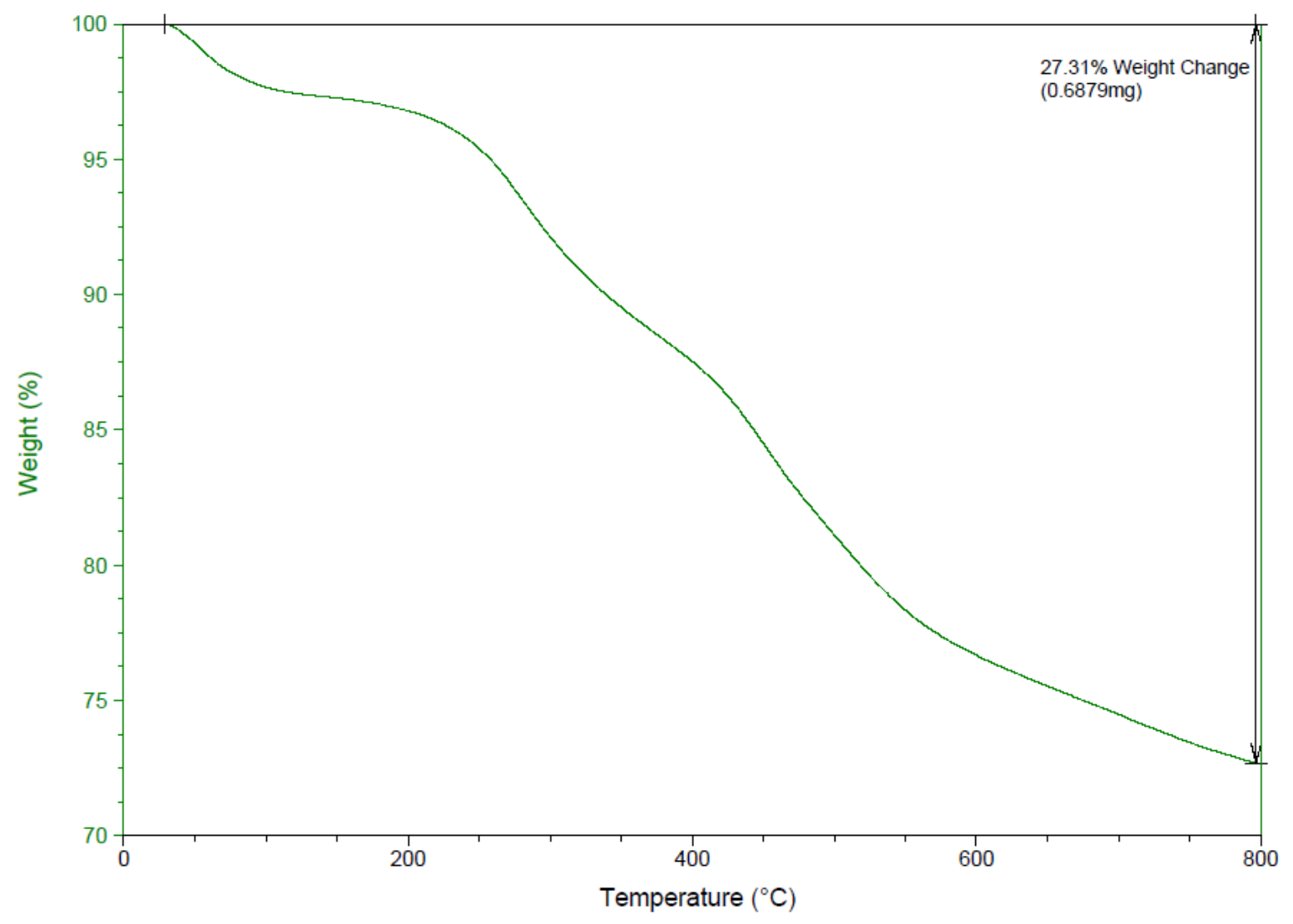

Fig. 1 (b) 


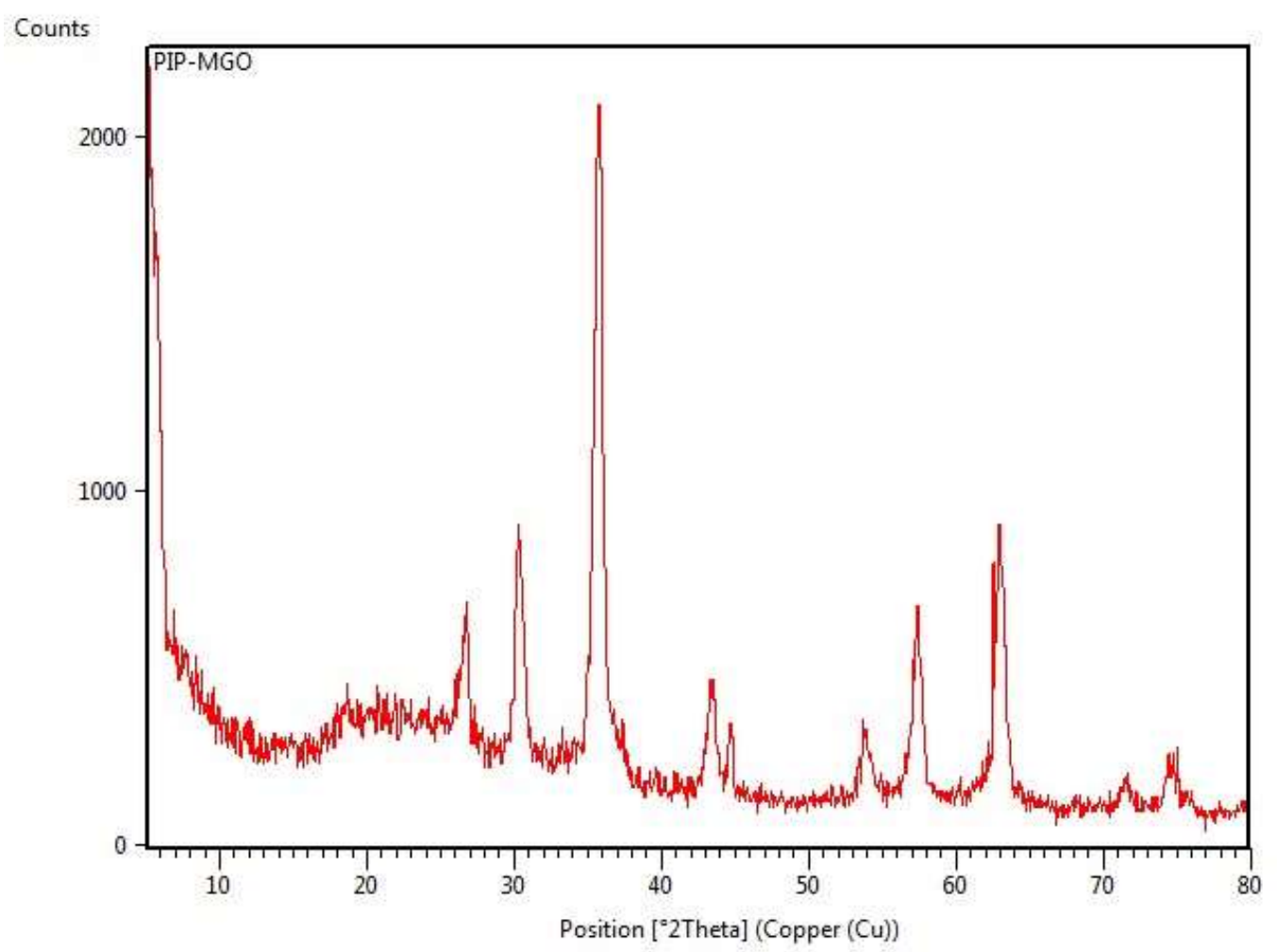

Fig. 1 (c)

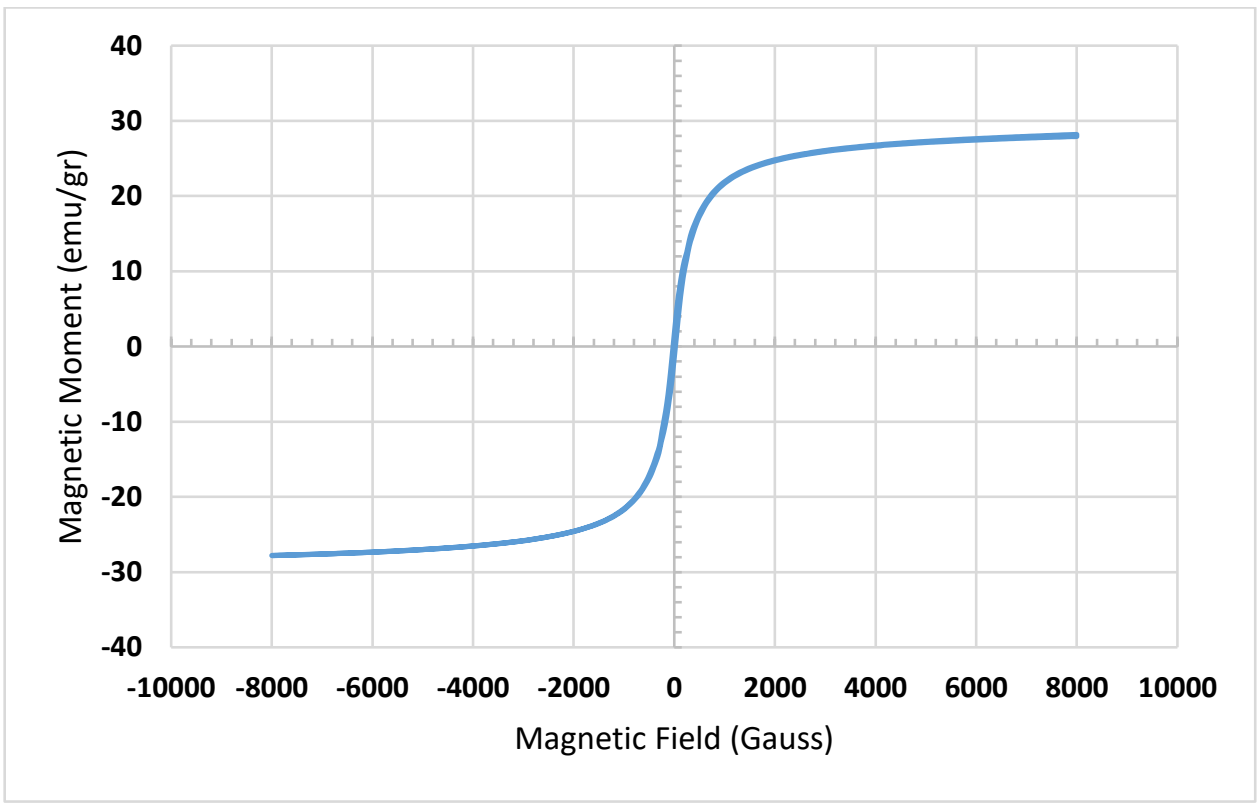

Fig. 1 (d) 

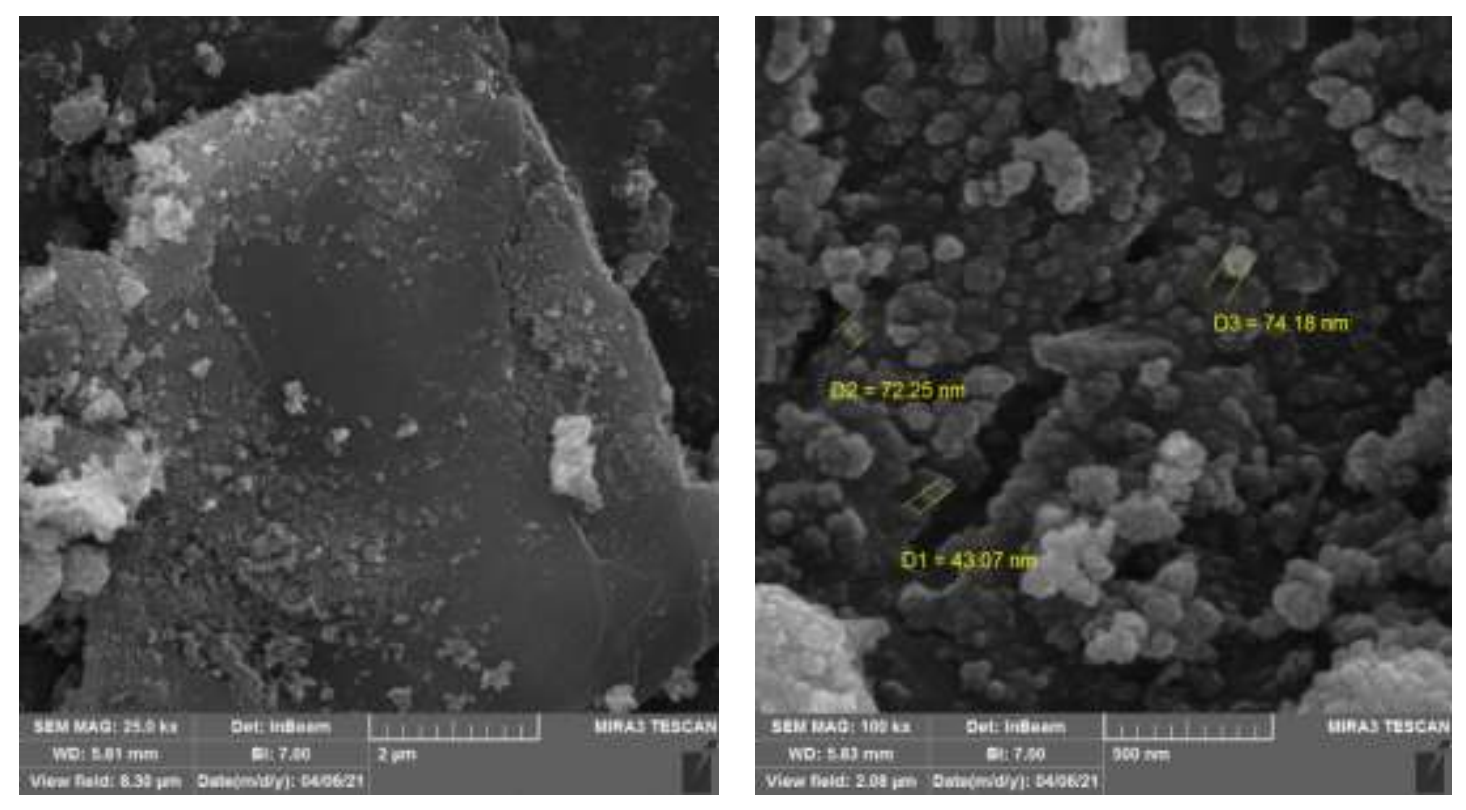

Fig. 2 

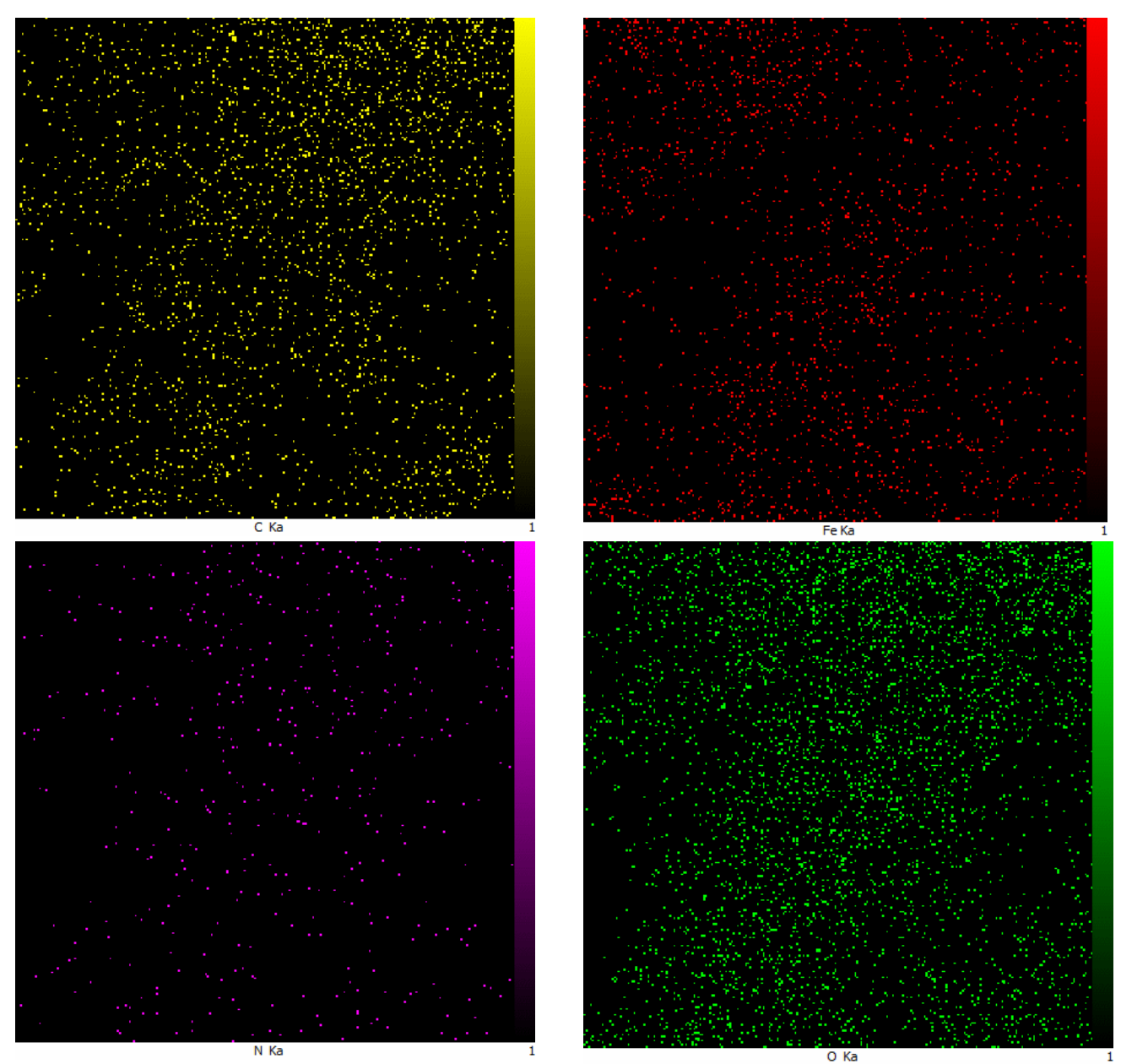

Fig. 3 (a) 


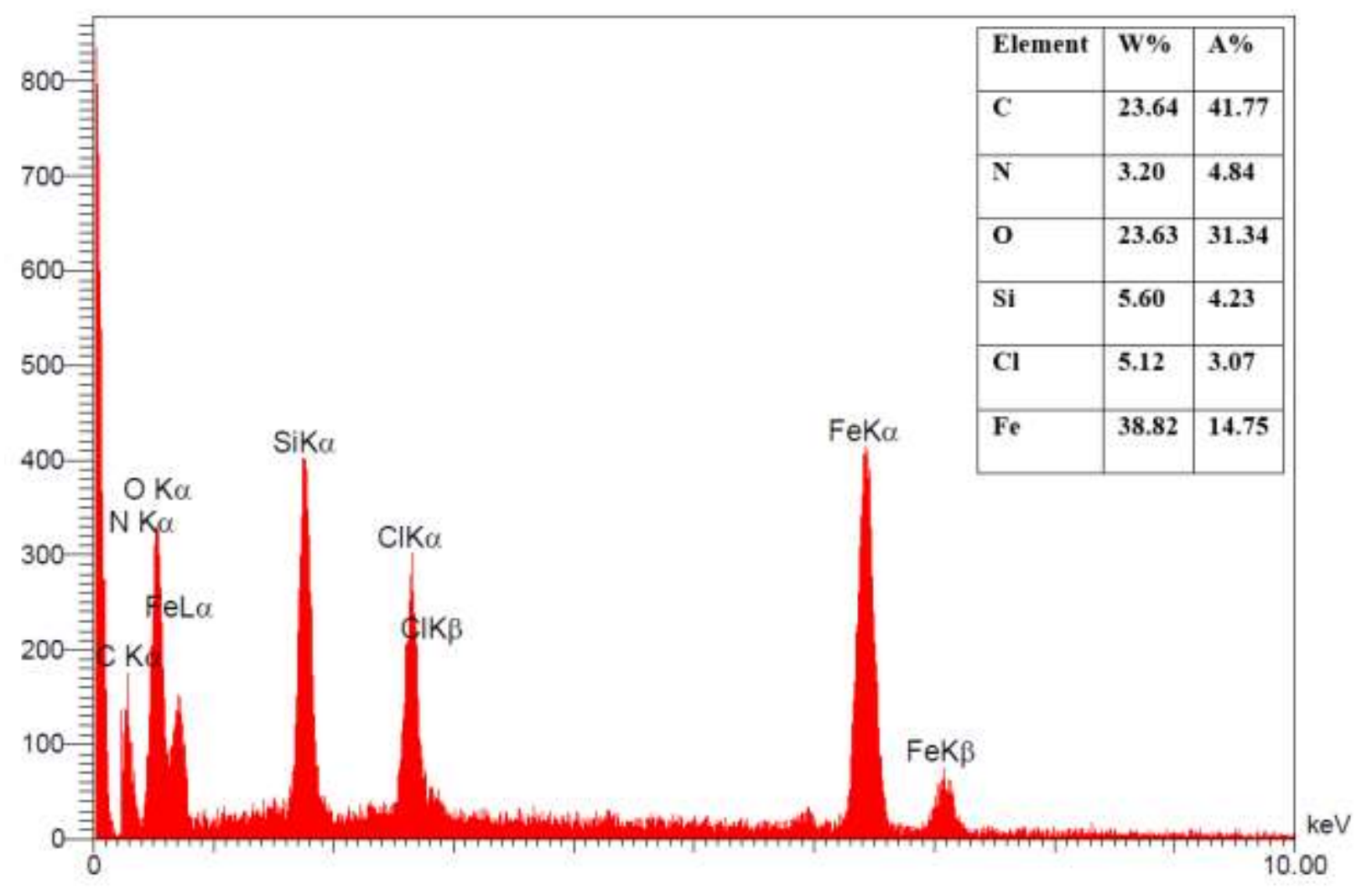

Fig. 3 (b) 


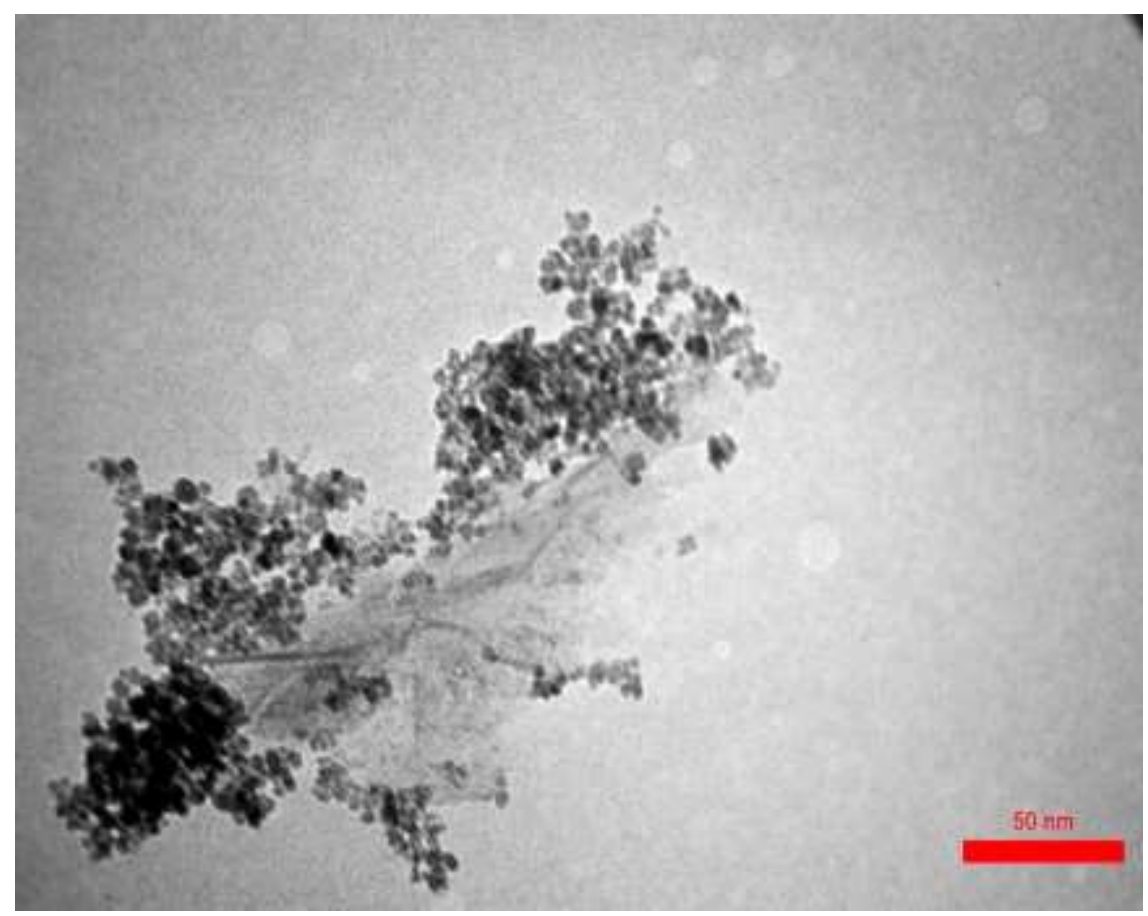

Fig. 4 
(a)

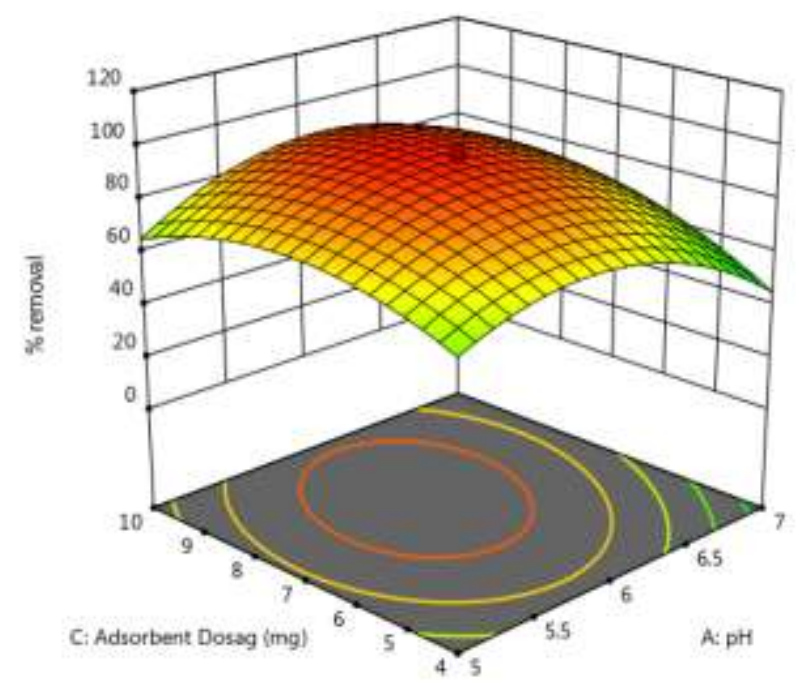

(c)

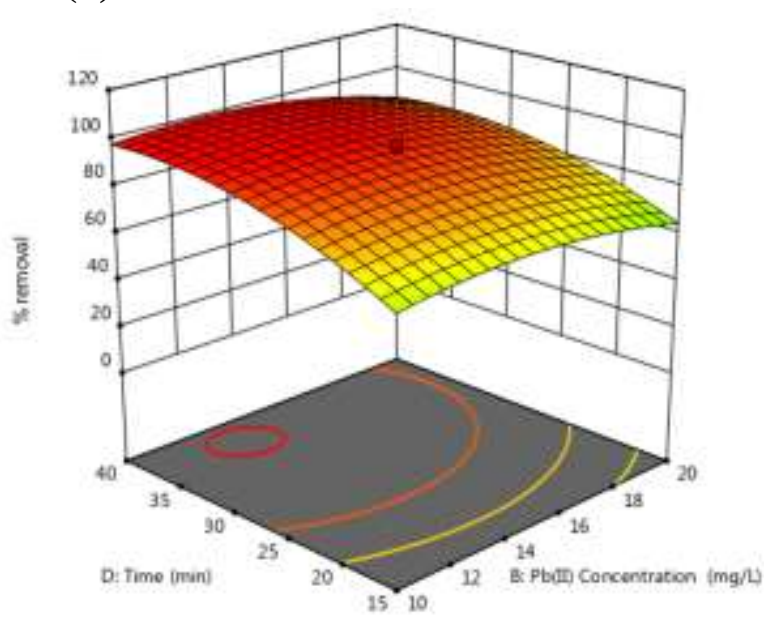

(b)

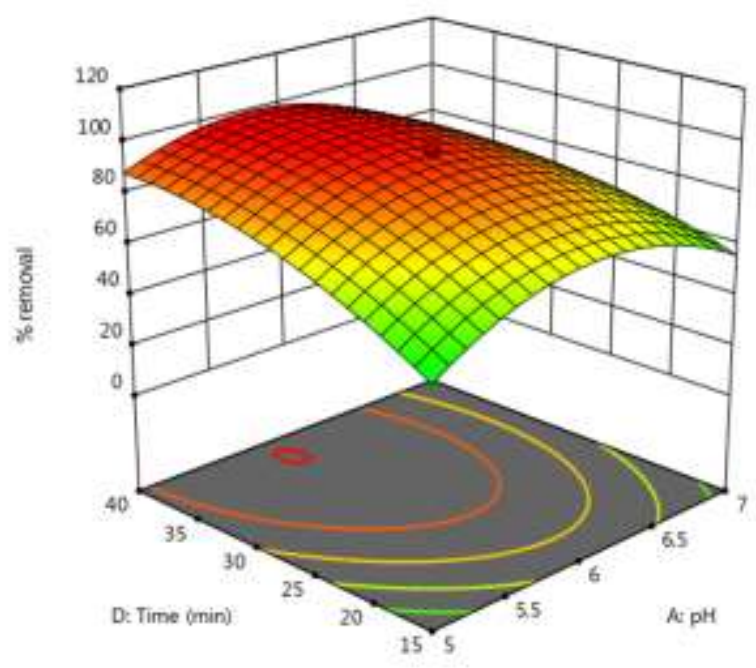

(d)

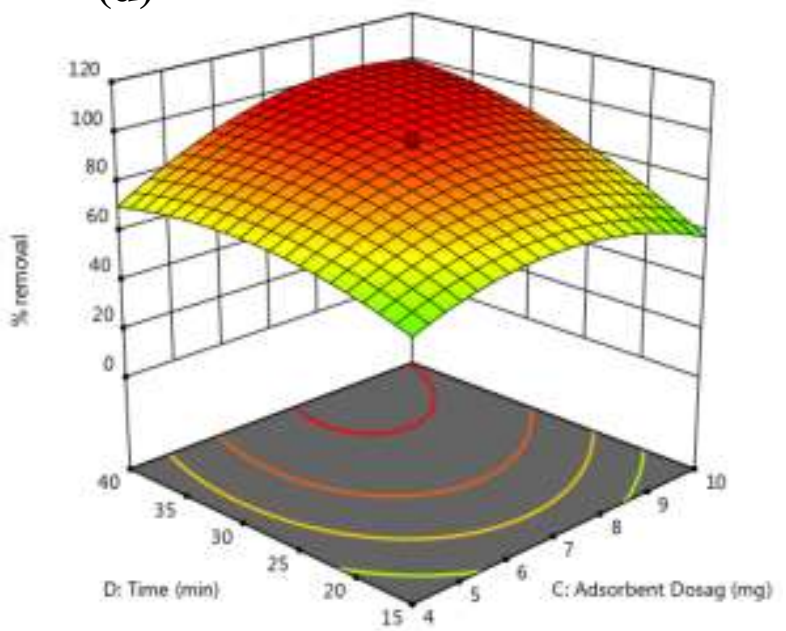

Fig. 5 